\title{
Qualitative and Quantitative Analyses of Volatile Compounds in Cream Cheese and Cholesterol-removed Cream Cheese Made from Whole Milk Powder
}

\author{
Seon-Suk Jeon, Seung-Joo Lee ${ }^{1}$, Palanivel Ganesan, and Hae-Soo Kwak* \\ Department of Food Science and Technology, Sejong University, Seoul 143-747, Korea \\ ${ }^{1}$ Department of Food Service Management, Sejong University, Seoul 143-747, Korea
}

\begin{abstract}
This study was to identify and quantify the flavor compounds in cream cheese and cholesterol-removed cream cheese made from whole milk powder stored at $7^{\circ} \mathrm{C}$ for $4 \mathrm{wk}$. Flavor compounds of cream cheese were identified using gas chromatography mass spectroscopy and quantified by gas chromatography. The tentatively identified flavor compounds were mainly eight from fatty acids in cream cheese made from whole milk powder (CCWMP) and nine from fatty acids in cholesterol-removed cream cheese made from whole milk powder (CRCCWMP). In quantitative analysis of the flavor compounds, most of the volatile compounds were slightly increased during storage. $N$-Decanoic acid was produced only in CCWMP. On the basis of the results, it was concluded that the quality and quantity of flavor compounds in CCWMP and CRCCWMP have almost no adverse effects in comparison with that of whole milk-made cream cheese.
\end{abstract}

Key words: flavor, whole milk powder, cream cheese, cholesterol removal

\section{Introduction}

Various efforts have been made to characterize the flavor profiles of hard and semi-hard cheeses (Rychlik and Bosset, 2001; Van Leuven et al., 2008) but very few efforts were taken in determining the flavor compounds of cream cheese. To our knowledge, no report has been published concerning the flavor profiles of cream cheese made from the whole milk powder. Further the development of cheese flavor is a complex combination of microbial and a biochemical activity throughout the storage period which leads to the formation of a heterogeneous mixture of volatile and non-volatile compounds (Adda, 1986; Molimard and Spinnler, 1996). In cream cheese most of the flavor derives from the lactic acid fermentation and from other rich nutrients such as protein and fat (Molimard and Spinnler, 1996). The fat reduction in cheeses leads to less acceptable than the full fat counterparts due to flavor defects (Kondyli et al., 2002). The lack of flavor is due to the precursors or solvent power

*Corresponding author: Hae-Soo Kwak, Department of Food Science and Technology, Sejong University, Seoul 143-747, Korea. Tel: 82-2-3408-3226, Fax: 82-2-3408-4319, E-mail: kwakhs@sejong.ac.kr lack from the fat that allows the release of essential volatile compounds (Urbach, 1997). However, cholesterolreduced cream cheese flavor from whole milk powder is not yet reported. Additionally, whole milk powder is usually made by high heat treatment; the formation of cooked flavor could be possible. Therefore, whole milk powder has not been tried to use for cheese making. But nowadays vacuum system was developed to lower temperature for heat treatment; thereby cooked flavor could be possibly reduced from the whole milk powder.

The quantitative measurement is of prime importance. Among the techniques used headspace gas chromatography (GC) is very effective, least destructive which provides volatile profile similar to the flavor characteristics perceived by the nose (Chin et al., 1996). This technique has been widely used to evaluate the flavor components in various cheeses (Alewijn et al., 2003). Therefore, the main objectives of this study were 1) to identify the volatile flavor compounds that are in headspace gases of cream cheese and 2) to compare the changes in the composition and concentration flavor profiles of cream cheese and cholesterol-removed cream cheese made from whole milk powder during $4 \mathrm{wk}$ storage. 


\section{Materials and methods}

\section{Materials}

Whole milk powder and cream ( $40 \%$ milk fat) were obtained from Seoul Dairy Co-op. (Korea). All solvents were of gas-chromatographic grade. Cholesterol and $5 \alpha-$ cholestane were purchased from Sigma Chemical Co. (USA), and all solvents were of gas-chromatographic grade.

\section{Manufacture of cream cheese}

Cream cheese from whole milk was produced according to the method of Kosikowski and Mistry (1997). For the preparation of cholesterol-removed cream cheese from whole milk powder (CRCCWMP), the whole milk powder was reconstituted to $87 \%$ water and blended with fresh cream ( $40 \%$ milk fat) to a fat content of $11 \%$ which was then pasteurized at $65^{\circ} \mathrm{C}$ for $30 \mathrm{~min}$. The blended mixture of whole milk powder and cream was stirred with $3.6 \%$ crosslinked $\beta$-cyclodextrin $(\beta-C D)$ at $800 \mathrm{rpm}$ with a blender (Tops, Misung Co., Korea) in a temperature-controlled water bath at $20^{\circ} \mathrm{C}$ for $30 \mathrm{~min}$. It was then centrifuged at $166 \times \mathrm{g}$ for the $\beta$-CD removal. Cholesterolremoved whole milk powder mixture of cream was homogenized $\left(680 \mathrm{psi}\right.$ at $\left.50^{\circ} \mathrm{C}\right)$ and cooled to the incubation temperature of approximately $30^{\circ} \mathrm{C}$. The mixture was then inoculated with a $0.05 \%$ lactic culture $(\mathrm{CNN}-22$, Chr. Hansen's Lab., Denmark) and incubated under gentle mixing. The curd was cut and ripened for $7 \mathrm{~h}$ to $\mathrm{pH}$ of 4.7. Then it was heated in a coil vats to about $45^{\circ} \mathrm{C}$ until a proper "break" is obtained between the curd and the whey. Whey was drained and the curd was cooled to $28^{\circ} \mathrm{C}$ for $4 \mathrm{~h}$ with continuous turning. The curd was drained in muslin bags and pressed until total solid was $45 \%$ and stored in plastic tubs at $7^{\circ} \mathrm{C}$ for $4 \mathrm{wk}$. The whole milk powder mixture of cream without treating with the $\beta$-CD was used as the cream cheese made from the whole milk powder (CCWMP). Both cheeses were made in duplicate.

\section{Composition analyses}

The samples of CCWMP and CRCCWMP were analyzed for moisture, protein and fat according to the methods of the Association of Official Analytical Chemists (AOAC, 1984). The cheese yield was determined in percentage as wt cheese $\times 100 / \mathrm{wt}$ of reconstituted milk and cream. Cholesterol was extracted and determined using silica fused capillary column (HP-5, $30 \mathrm{~m} \times 0.32 \mathrm{~mm}$ I.D. $\times$ $0.25 \mu \mathrm{m}$ thickness) using a Hewlett-Packard 5890 A gas chromatograph (Hewlett-Packard, USA) equipped with a flame ionization detector. The quantification of cholesterol was done by comparing the peak areas with the response of internal standard. The percentage of cholesterol reduction was calculated as follows: cholesterol reduction $(\%)=100-$ (amount of cholesterol in $\beta-C D$ treated cream cheese $\times 100$ /amount of cholesterol in cream cheese). Cholesterol determination for cream cheese was averaged with each batch of treatments.

\section{Identification of volatile compound (solid phase microextraction GC-MS)}

The volatile compounds in whole milk cream cheese, cholesterol removed whole milk cream cheese, CCWMP and CRCCWMP were extracted by solid phase microextraction. The cheese samples were grated and ten grams of each cheese were placed in a 50-mL vial contains 10 $\mathrm{mL} \mathrm{NaH} \mathrm{PO}_{4}(25 \%$, w/v) along with $7 \mathrm{~mL}$ of distilled water and $1 \mathrm{~mL}$ of internal standard (IS) [5-nonanon (10 $\mu \mathrm{g} / \mathrm{mL}$ in methanol)]. The sample was stirred at $60^{\circ} \mathrm{C}$ for $30 \mathrm{~min}$ to accelerate equilibrium of headspace flavor compounds between the cheese matrix and the headspace. Then, flavor compounds extraction was carried out by injecting a 50/30 $\mu \mathrm{m}$ divinylbenzene/carboxen/polydimethylsiloxane SPME fibre (Supelco, USA) into the vial and exposing it to the headspace at $50^{\circ} \mathrm{C}$ for $30 \mathrm{~min}$. After extraction samples were then desorbed and identified by GC-MS according to the modified method of Lee et al. (2003). The analyses of flavor compounds were performed on a Hewlett-Packard gas chromatograph (HP6890 GC) coupled to a Hewlett-Packard 5973 MS (HewlettPackard, USA). Flavor compounds were separated using a capillary column (DB-Wax; $30 \mathrm{~m} \times 0.33 \mathrm{~mm}$ I.D. $\times 0.25$ $\mu \mathrm{m}$ film thickness; J\&W Scientific Inc., USA). The carrier gas was helium with a flow of $1.3 \mathrm{~mL} / \mathrm{min}$. The temperature programmed was isothermal at $40^{\circ} \mathrm{C}$ for $4 \mathrm{~min}$, then raised at $5^{\circ} \mathrm{C} / \mathrm{min}$ to $185^{\circ} \mathrm{C}$ and held for $20 \mathrm{~min}$. The GC-MS transfer line temperature was at $230^{\circ} \mathrm{C}$. The MS operated in electron impact mode with electron impact energy of $70 \mathrm{eV}$; and collected data at a rate of $0.7 \mathrm{scans} / \mathrm{s}$ over a range of $\mathrm{m} / \mathrm{z}$ 40-650. The compounds were identified by comparison with commercial reference compounds provided by Wiley 275 Mass spectral database (HewlettPackard, USA). Quantitation of CCWMP and CRCCWMP was performed by integrating the peak areas of total ion chromatograms by the Agilent ChemStation software.

Analysis of short-chain free fatty acids (SCFFA) SCFFA of each cheese samples were quantified using a 
DS6200 GC (Korea) on a $15 \mathrm{~m} \times 0.53 \mathrm{~mm}$ I.D. Nukol fusedsilica capillary column (Supelco Inc., USA) equipped with a flame ionization detector with direct on column injection as described by Kwak et al. (1990). SCFFA was identified by comparison with the retention time of a standard. The quantitation of the SCFFA of cheese samples was performed using the internal standardization technique with crotonic acid as an internal standard and processing the chromatograms with the DSCHROM 2000 Chromatography Laboratory Automated Software System (Donam Instruments Inc., Korea).

\section{Statistical analysis}

All statistical analyses were performed using SAS version 9.0 (SAS, 2002). An ANOVA was performed using the general linear models procedure to determine significant differences among the samples. Means were compared by using Duncan's multiple range test $(p<0.05)$.

\section{Results and Discussion}

\section{Chemical composition and yield}

The chemical composition, cheese yield and cholesterol removal rate of CCWMP and CRCCWMP were presented in Table 1. The moisture, protein, fat content and cheese yield showed similar ratio between the cheeses. The cholesterol content of the CCWMP was $96.28 \mathrm{mg} /$ $100 \mathrm{~g}$. The cholesterol reduction rate of CRCCWMP
Table 1. Chemical compositions of cream cheese and cholesterol-removed cream cheese made from whole milk powder

\begin{tabular}{lrr}
\hline \hline \multicolumn{1}{c}{ Components } & CCWMP* & CRCCWMP** \\
\hline Moisture (\%) & $58.30 \pm 0.29$ & $58.50 \pm 0.50$ \\
Protein (\%) & $7.97 \pm 0.10$ & $7.96 \pm 0.12$ \\
Fat (\%) & $33.68 \pm 0.11$ & $33.53 \pm 0.11$ \\
Cheese yield (\%) & $36.18 \pm 0.15$ & $36.20 \pm 0.14$ \\
Cholesterol (mg/100 g) & $96.28 \pm 0.13$ & $7.47 \pm 0.09$ \\
Cholesterol removal (\%) & - & $92.80 \pm 0.21$ \\
\hline
\end{tabular}

*CCWMP, cream cheese made from whole milk powder

**CRCCWMP, cholesterol-removed cream cheese made from whole milk powder

reached $92.80 \%$ by using crosslinked $\beta$-CD. It was well correlated with our previous study which also showed similar reduction of cholesterol in milk and mayonnaise (Han et al., 2005; Jung et al., 2008). Similar cholesterol reductions were also found in Blue cheese by crosslinked $\beta$-CD without any significant change in the flavor, color and sensory properties (Kim et al., 2008). In our preliminary study the cream cheese made with whole milk showed similar compositions and cholesterol reduction through cross linked $\beta$-CD. It also confirmed that cholesterol reduction by cross linked $\beta-\mathrm{CD}$ did not effect the approximate composition of CCWMP.

\section{Volatile components identified by GC/MS}

The volatiles in the whole milk cream cheese, choles-

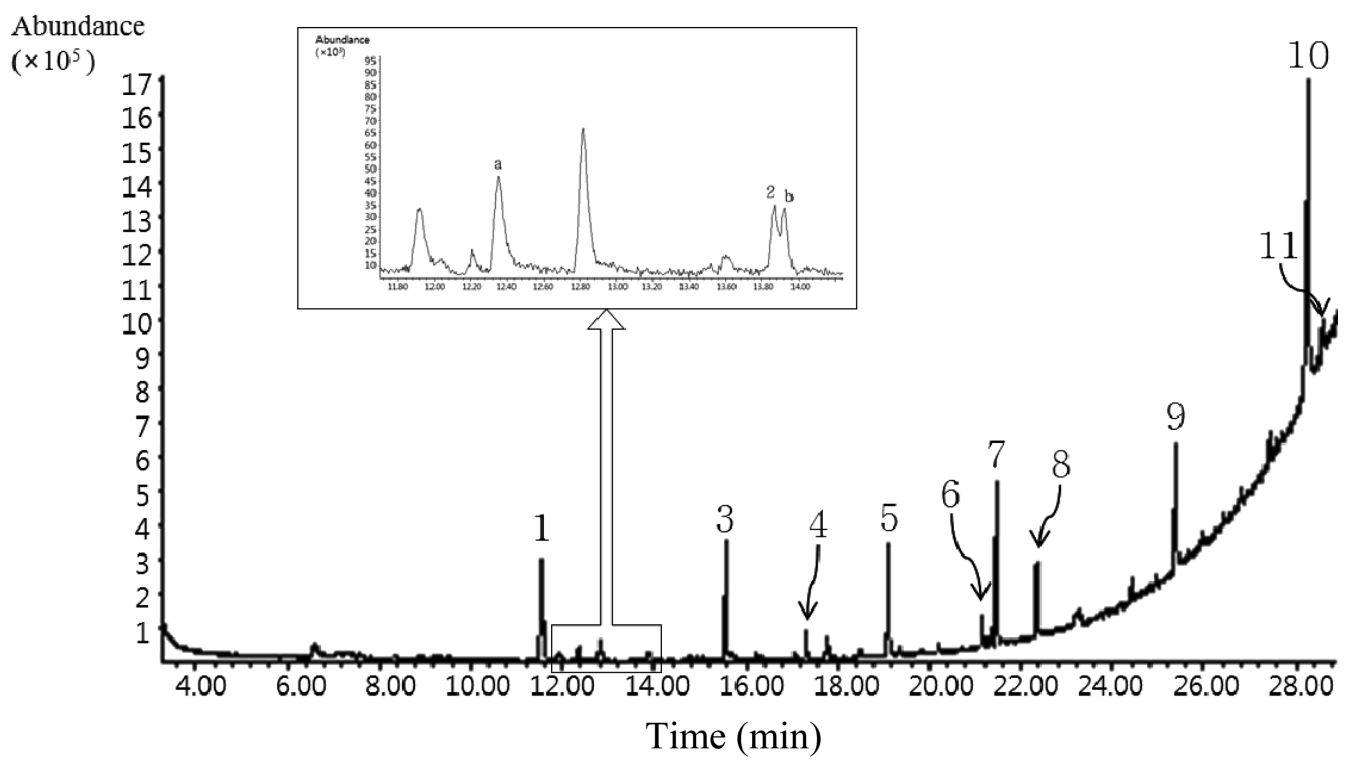

Fig. 1. Chromatogram of identified volatile compounds from cream cheese made from whole milk during storage at $7^{\circ} \mathrm{C}$ for 4 wk. [1] hexanoic acid; [2] 2-tridecanone; [a] 5-(p-aminophenyl)-4-(o-tolyl)-2-thiazolamine; [b] phenol, 4,6-di(1,1-dimethylenthyl)-2-methyl; [3] octanoic acid [4] 2-pentadecanone; [5] $n$-decanoic acid; [6] 2H-pyran-2-one, tetrahydro-6-pentyl; [7] benzoic acid; [8] dodecanoic acid; [9] tetradecanoic acid; [10] tridecanoic acid; [11] $n$-hexadecanoic acid 
terol-removed whole milk cream cheese, CCWMP and CRCCWMP were isolated using headspace solid-phase microextraction (HS-SPME) and then analyzed by GCMS for the identification. Fig. 1, 2, 3, and 4 showed the tentatively identified flavor components in each of the four samples during $4 \mathrm{wk}$ storage at $7^{\circ} \mathrm{C}$ by their peak numbers in comparison with commercial reference compounds provided by Wiley 275 Mass spectral database. In the whole milk cream cheese, a total of 13 flavor components, including, 8 fatty acids, 2 ketones, 1 amine, 1 lactone and 1 miscelleanous compounds were identified during 4 wk storage (Fig. 1). In the CCWMP, a total of 11 flavor components, including 8 fatty acids, 2 ketones and 1 miscelleanous compounds (Fig. 3). In the whole milk cholesterol-removed cream cheese, a total of 15 flavor components, including, 11 fatty acids, 2 ketones and 2

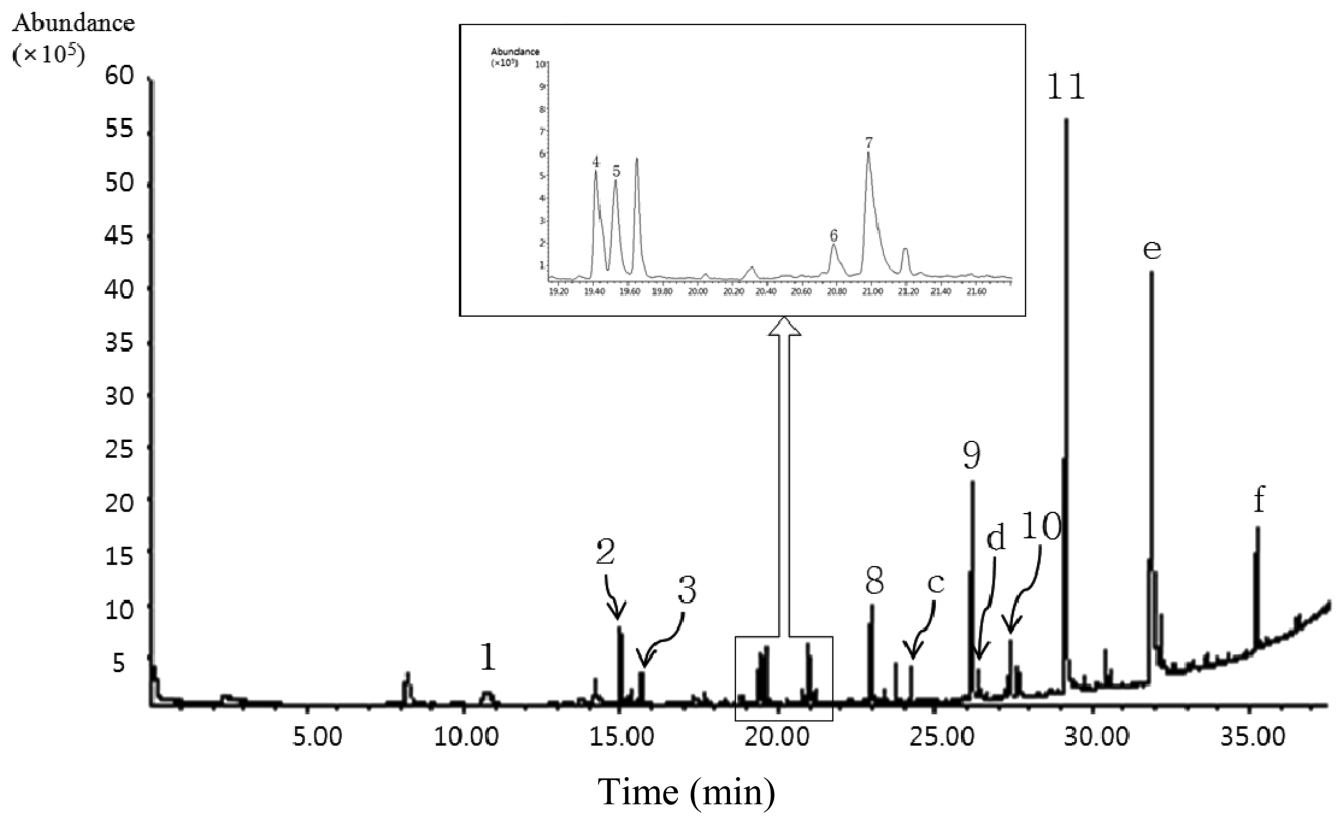

Fig. 2. Chromatogram of identified volatile compounds from cholesterol-removed cream cheese made from whole milk during storage at $7^{\circ} \mathbf{C}$ for $4 \mathbf{~ w k}$. [1] hexanoic acid; [2] 2-tridecanone; [3] octanoic acid [4] 2-pentadecanone; [5] $n$-decanoic acid; [6] 2H-pyran-2-one, tetrahydro-6-pentyl; [7] benzoic acid; [8] dodecanoic acid; [c] 2H-pyran-2-one, 6-heptyltetrahydro; [9] tetradecanoic acid; [d] z-11-tetradecenoic acid; [10] tridecanoic acid; [11] $n$-hexadecanoic acid; [e] q-octadecenoic acid; [f] 9, 12-octadecadienoic acid

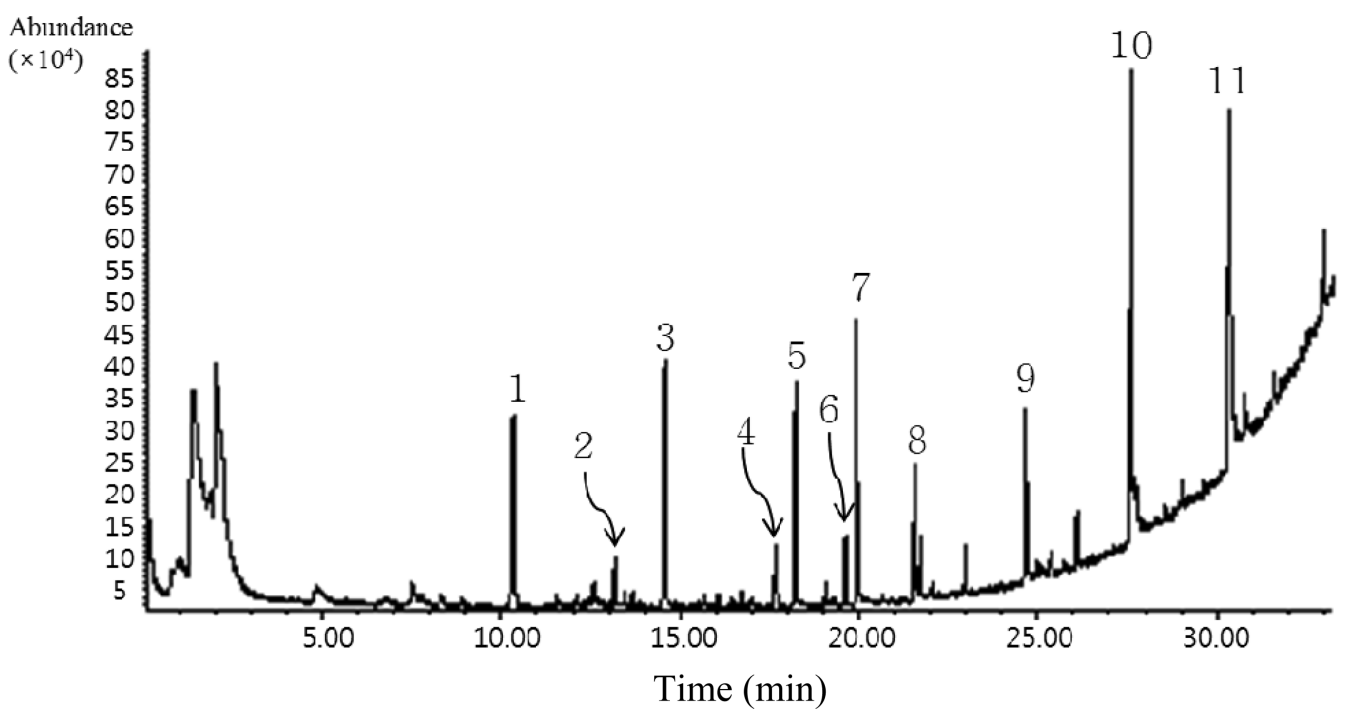

Fig. 3. Chromatogram of identified volatile compounds from cream cheese made from whole milk powder during storage at $7^{\circ} \mathrm{C}$ for 4 wk. [1] hexanoic acid; [2] 2-tridecanone; [3] octanoic acid [4] 2-pentadecanone; [5] $n$-decanoic acid; [6] 2H-pyran-2-one, tetrahydro-6-pentyl; [7] benzoic acid; [8] dodecanoic acid; [9] tetradecanoic acid; [10] $n$-hexadecanoic acid; [11] q-octadecenoic acid 


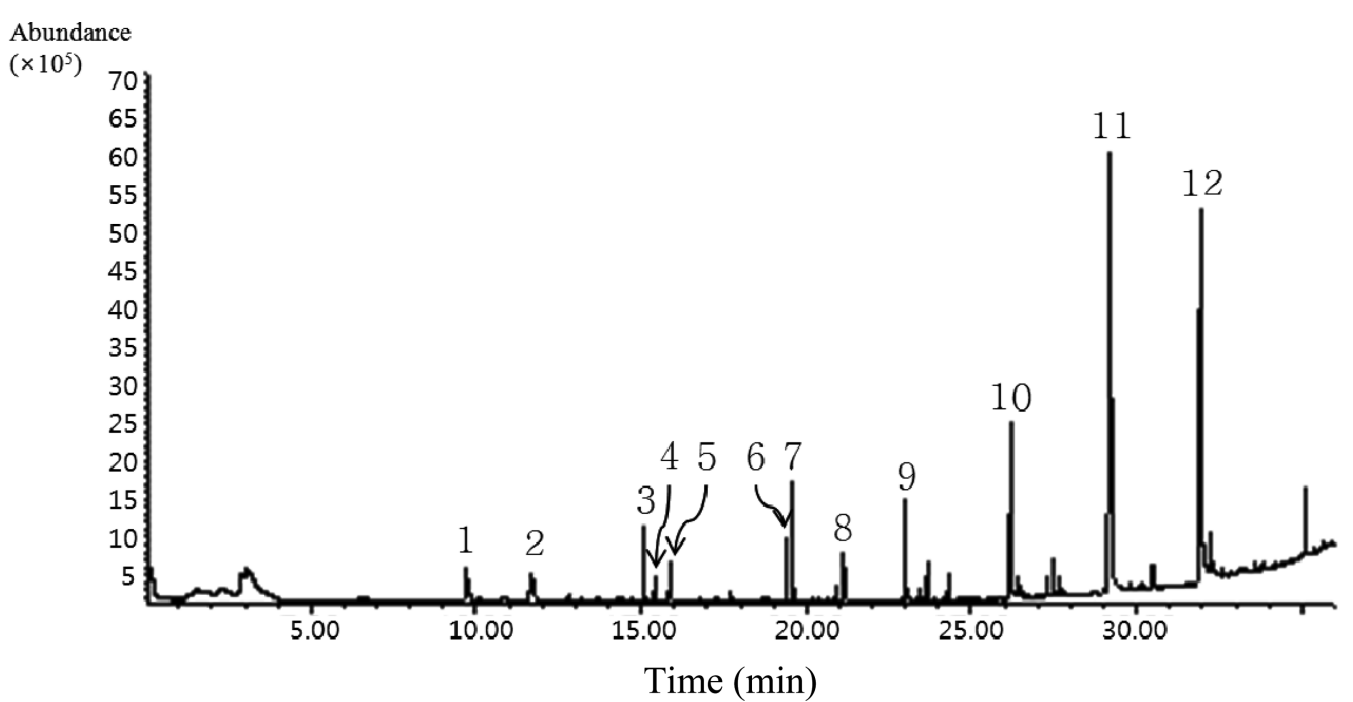

Fig. 4. Chromatogram of identified volatile compounds from cholesterol-removed cream cheese made from whole milk powder during storage at $7^{\circ} \mathbf{C}$ for $4 \mathbf{~ w k}$. [1] hexanoic acid; [2] 2-tridecanone; [3] octanoic acid [4] 2-pentadecanone; [5] benzoic acid; [6] dodecanoic acid; [7] 2H-pyran-2-one, 6-heptyltetrahydro; [8] tetradecanoic acid; [9] z-7-tetradecenoic acid; [10] pentadecanoic acid; [11] $n$-hexadecanoic acid; [12] q-octadecenoic acid

lactone (Fig. 2). In the CRCCWMP, a total of 12 flavor components, including 9 fatty acids, 2 ketones and 1 miscelleanous compounds, were identified (Fig. 4).

In general, whole milk-made cream cheese contains higher amount of flavor compounds than the CCWMP (Urbach, 1997). This was most expected since during preparation of whole milk powder some amount of flavor compounds can be lost. Among the identified flavors, fatty acids were the largest group. However, $n$-decanoic acids were detected only in the whole milk-made cream cheese and CCWMP, while z-7-tetradecenoic acid and pentadecanoic acid were only identified in the CRCCWMP. Similar flavor compounds were also identified in other cheeses such as Spanish soft cheese (Delgado et al., 2010) and Cheddar cheese (Carunchia Whetstine et al., 2006). Fat-rich cream leads to the lipolysis during fermentation and leads to the liberation of certain fatty acids with increasing storage period of cheese (Delgado et al., 2010). It was well correlated with the chemical composition of the CCWMP and CRCCWMP with higher fat content (Table 1).

\section{Quantification of volatile compounds}

The volatiles in the CCWMP and CRCCWMP were quantified and are listed in Table 2. Among the quantified volatiles in cheeses fatty acid found to be greater concentrations than ketones and other miscellaneous compounds. In fatty acids, $n$-hexadecanoic acid found to be higher level in CRCCWMP than CCWMP during 4 wk storage. In contrast, the concentrations of other fatty acids such as octanoic acid, benzoic acid, dodecanoic acid and tetradecanoic acid found to be lower level in CRCCWMP than CCWMP $(p<0.05)$. The levels of two ketones and miscellaneous compounds were also increased during 4 wk storage in both samples. Overall concentrations of the flavor compounds in CRCCWMP were less different from those in the CCWMP.

In examining aromas of detected fatty acids, hexanoic acid is described as having pungent, blue cheese and green odors, while octanoic acid having goaty, waxy, soapy and musty odors (Delgado et al., 2010). Decanoic acid and dodecanoic acid exhibited generally rancid and fatty odors. Considering low volatilities and high threshold levels of longer free fatty acids like tetradecanoic acid, hexadecanoic acid, oleic acid and linoleic acid, the contribution would be limited to aroma of cream cheese. Two ketones, 2-tridecanone and 2-pentadecanone were identified in this study. Ketones can be generated by enzymatic actions on lipids and/or amino acids or by the Maillard reaction which are more common constituents in dairy products (Carbonell et al., 2002). Although the flavor notes of these ketones are generally desirable such as fruity, green, slightly spicy and floral, their aroma contributions might have been minimal since low levels of these compounds were quantified.

\section{SCFFA}

The SCFFA in CCWMP and CRCCWMP stored at $7^{\circ} \mathrm{C}$ for $4 \mathrm{wk}$ were presented in Table 3. SCFFA are found to be the major volatile compounds in most of the cheeses 
Table 2. Concentrations of volatile flavor compounds in cream cheese and cholesterol-removed cream cheese made from whole milk powder during storage at $7^{\circ} \mathrm{C}$ for $4 \mathrm{wk}^{1}$

(unit : ppm)

\begin{tabular}{|c|c|c|c|c|c|c|c|c|c|c|}
\hline \multirow{3}{*}{ Volatile compounds } & \multicolumn{10}{|c|}{ Storage period (wk) } \\
\hline & \multicolumn{2}{|c|}{0} & \multicolumn{2}{|c|}{1} & \multicolumn{2}{|c|}{2} & \multicolumn{2}{|c|}{3} & \multicolumn{2}{|c|}{4} \\
\hline & CCWMP & $\begin{array}{c}\text { CRC- } \\
\text { CWMP }^{3}\end{array}$ & CCWMP & $\begin{array}{l}\text { CRC- } \\
\text { CWMP }\end{array}$ & CCWMP & $\begin{array}{l}\text { CRC- } \\
\text { CWMP }\end{array}$ & CCWMP & $\begin{array}{l}\text { CRC- } \\
\text { CWMP }\end{array}$ & CCWMP & $\begin{array}{l}\text { CRC- } \\
\text { CWMP }\end{array}$ \\
\hline \multicolumn{11}{|l|}{ Fatty acid } \\
\hline Hexanoic acid & $0.100^{\mathrm{a}}$ & $0.113^{\mathrm{b}}$ & $0.106^{\mathrm{a}}$ & $0.116^{\mathrm{b}}$ & $0.149^{\mathrm{a}}$ & $0.136^{\mathrm{ab}}$ & $0.157^{\mathrm{a}}$ & $0.145^{\mathrm{ab}}$ & $0.145^{\mathrm{a}}$ & $0.159^{\mathrm{a}}$ \\
\hline Octanoic acid & $0.195^{\mathrm{c}}$ & $0.117^{\mathrm{b}}$ & $0.219^{\mathrm{bc}}$ & $0.120^{\mathrm{ab}}$ & $0.236^{\mathrm{ab}}$ & $0.131^{\mathrm{ab}}$ & $0.253^{\mathrm{a}}$ & $0.144^{\mathrm{ab}}$ & $0.259^{\mathrm{a}}$ & $0.150^{\mathrm{a}}$ \\
\hline$n$-Decanoic acid & $0.065^{\mathrm{b}}$ & - & $0.080^{\mathrm{b}}$ & - & $0.102^{\mathrm{ab}}$ & - & $0.123^{\mathrm{a}}$ & - & $0.131^{\mathrm{a}}$ & - \\
\hline Benzoic acid & $0.104^{\mathrm{a}}$ & $0.051^{\mathrm{c}}$ & $0.111^{\mathrm{a}}$ & $0.056^{\text {bc }}$ & $0.113^{\mathrm{a}}$ & $0.061^{\mathrm{abc}}$ & $0.142^{\mathrm{a}}$ & $0.070^{\mathrm{ab}}$ & $0.146^{\mathrm{a}}$ & $0.074^{\mathrm{a}}$ \\
\hline Dodecanoic acid & $0.103^{\mathrm{bc}}$ & $0.105^{\mathrm{b}}$ & $0.106^{\mathrm{abc}}$ & $0.115^{\mathrm{ab}}$ & $0.106^{\mathrm{abc}}$ & $0.124^{\mathrm{ab}}$ & $0.115^{\mathrm{ab}}$ & $0.138^{\mathrm{ab}}$ & $0.130^{\mathrm{a}}$ & $0.159^{\mathrm{a}}$ \\
\hline Tetradecanoic acid & $0.106^{\mathrm{b}}$ & $0.098^{\mathrm{a}}$ & $0.123^{\mathrm{ab}}$ & $0.106^{\mathrm{a}}$ & $0.135^{\mathrm{ab}}$ & $0.110^{\mathrm{a}}$ & $0.145^{\mathrm{ab}}$ & $0.118^{\mathrm{a}}$ & $0.156^{\mathrm{a}}$ & $0.120^{\mathrm{a}}$ \\
\hline Z-7-Tetradecenoic acid & - & - & - & - & - & - & - & - & - & $0.079^{\mathrm{a}}$ \\
\hline Pentadecanoic acid & - & $0.079^{\mathrm{b}}$ & - & $0.083^{\mathrm{ab}}$ & - & $0.084^{\mathrm{ab}}$ & - & $0.086^{\mathrm{ab}}$ & - & $0.089^{\mathrm{a}}$ \\
\hline$n$-Hexadecanoic acid & $0.204^{\mathrm{b}}$ & $0.311^{\mathrm{c}}$ & $0.216^{\mathrm{ab}}$ & $0.337^{\mathrm{bc}}$ & $0.229^{\mathrm{ab}}$ & $0.351^{\mathrm{abc}}$ & $0.250^{\mathrm{ab}}$ & $0.366^{\mathrm{ab}}$ & $0.272^{\mathrm{a}}$ & $0.393^{\mathrm{a}}$ \\
\hline q-octadecenoic & $0.163^{\mathrm{a}}$ & $0.175^{\mathrm{c}}$ & $0.172^{\mathrm{a}}$ & $0.183^{\text {bc }}$ & $0.177^{\mathrm{a}}$ & $0.204^{\mathrm{ab}}$ & $0.180^{\mathrm{a}}$ & $0.208^{\mathrm{ab}}$ & $0.182^{\mathrm{a}}$ & $0.229^{\mathrm{a}}$ \\
\hline \multicolumn{11}{|l|}{$\overline{\text { Ketone }}$} \\
\hline 2-Tridecanone & $0.051^{\mathrm{b}}$ & $0.099^{\mathrm{a}}$ & $0.052^{\mathrm{b}}$ & $0.105^{\mathrm{a}}$ & $0.055^{\mathrm{ab}}$ & $0.110^{\mathrm{a}}$ & $0.057^{\mathrm{ab}}$ & $0.115^{\mathrm{a}}$ & $0.060^{\mathrm{a}}$ & $0.116^{\mathrm{a}}$ \\
\hline 2-Pentadecanone & $0.069^{\mathrm{c}}$ & $0.122^{\mathrm{a}}$ & $0.111^{\mathrm{b}}$ & $0.134^{\mathrm{a}}$ & $0.123^{\mathrm{b}}$ & $0.154^{\mathrm{a}}$ & $0.156^{\mathrm{a}}$ & $0.156^{\mathrm{a}}$ & $0.157^{\mathrm{a}}$ & $0.158^{\mathrm{a}}$ \\
\hline \multicolumn{11}{|l|}{ Miscellaneous compounds } \\
\hline 2H-Pyran-2-one, tetrahydro-6-pentyl & $0.090^{\mathrm{c}}$ & $0.098^{\mathrm{a}}$ & $0.099^{c}$ & $0.101^{\mathrm{a}}$ & $0.116^{\mathrm{b}}$ & $0.123^{\mathrm{a}}$ & $0.125^{\mathrm{ab}}$ & $0.136^{\mathrm{a}}$ & $0.140^{\mathrm{a}}$ & $0.141^{\mathrm{a}}$ \\
\hline
\end{tabular}

Table 3. Short-chain free fatty acid of cream cheese and cholesterol-removed cream cheese made from whole milk powder during storage at $7^{\circ} \mathrm{C}$ for $4 \mathrm{wk}^{1}$

(unit : ppm)

\begin{tabular}{ccccccc}
\hline \hline \multirow{2}{*}{ Treatment } & \multirow{2}{*}{ SCFFA $^{\wedge}$} & \multicolumn{5}{c}{ Storage period (wk) } \\
\cline { 3 - 7 } & & 0 & 1 & 2 & 3 & 4 \\
\hline CCWMP* $^{*}$ & \multirow{2}{*}{$\mathrm{C}_{4}$} & $19.27^{\mathrm{a}}$ & $19.51^{\mathrm{a}}$ & $19.68^{\mathrm{a}}$ & $20.60^{\mathrm{a}}$ & $21.63^{\mathrm{a}}$ \\
CRCCWMP $^{* *}$ & & $14.35^{\mathrm{b}}$ & $16.07^{\mathrm{a}}$ & $16.76^{\mathrm{a}}$ & $16.96^{\mathrm{a}}$ & $17.21^{\mathrm{a}}$ \\
\hline CCWMP & \multirow{2}{*}{$\mathrm{C}_{6}$} & $22.30^{\mathrm{b}}$ & $22.88^{\mathrm{ab}}$ & $23.59^{\mathrm{ab}}$ & $23.87^{\mathrm{a}}$ & $24.36^{\mathrm{a}}$ \\
CRCCWMP & & $19.08^{\mathrm{c}}$ & $19.44^{\mathrm{c}}$ & $19.65^{\mathrm{c}}$ & $20.50^{\text {ab }}$ & $20.63^{\mathrm{a}}$ \\
\hline CCWMP & \multirow{2}{*}{$\mathrm{C}_{8}$} & $8.27^{\mathrm{a}}$ & $8.47^{\mathrm{a}}$ & $8.63^{\mathrm{a}}$ & $8.72^{\mathrm{a}}$ & $9.05^{\mathrm{a}}$ \\
CRCCWMP & & $8.46^{\mathrm{a}}$ & $8.59^{\mathrm{a}}$ & $8.63^{\mathrm{a}}$ & $8.67^{\mathrm{a}}$ & $8.87^{\mathrm{a}}$ \\
\hline CCWMP & \multirow{2}{*}{$\mathrm{C}_{10}$} & $26.57^{\mathrm{c}}$ & $28.49^{\mathrm{bc}}$ & $29.45^{\mathrm{abc}}$ & $31.06^{\mathrm{ab}}$ & $32.17^{\mathrm{a}}$ \\
CRCCWMP & & $26.30^{\mathrm{b}}$ & $28.36^{\mathrm{ab}}$ & $28.86^{\mathrm{a}}$ & $29.55^{\mathrm{a}}$ & $30.25^{\mathrm{a}}$ \\
\hline CCWMP & \multirow{2}{*}{ Total } & $76.42^{\mathrm{d}}$ & $79.36^{\mathrm{c}}$ & $81.36^{\mathrm{c}}$ & $84.27^{\mathrm{b}}$ & $87.23^{\mathrm{a}}$ \\
CRCCWMP & & $68.21^{\mathrm{c}}$ & $72.47^{\mathrm{b}}$ & $73.91^{\mathrm{b}}$ & $75.70^{\mathrm{a}}$ & $76.98^{\mathrm{a}}$ \\
\hline
\end{tabular}

${ }^{1}$ Values with different letters within the same row differ significantly $(p<0.05)$.

*CCWMP, cream cheese made from whole milk powder

**CRCCWMP, cholesterol-removed cream cheese made from whole milk powder

$\triangle$ SCFFA: short-chain free fatty acids

(Patton, 1963). The SCFFA were found to be increased with increasing storage period of $4 \mathrm{wk}$ in both cheeses irrespective of treatments. However, the concentration of all SCFFA found to significantly higher in CCWMP than CRCCWMP $(p<0.05)$. The total amount of SCFFA in CRCCWMP was 76.98 ppm at 4 wk storage, which was equal to the CCWMP at $0 \mathrm{wk}$. In our previous study, we also reported that the lower amount of SCFFA in $\beta$-CD treated cream cheese made from whole milk was due to the fat structure loss during cholesterol removal in cream. The hexanoic acid in the CCWMP and CRCCWMP were 22.30 and $19.08 \mathrm{ppm}$ at the $0 \mathrm{wk}$, respectively. After $4 \mathrm{wk}$ of storage, the levels of hexanoic acid increased in both samples (24.36 and $20.63 \mathrm{ppm}$, respectively). The con- 
centration of these fatty acids increases during storage is due to the lipolysis (Attaie, 2009). These acids not only contribute volatile flavor but also lead to the sour taste of several cheeses (Carunchia Whetstine et al., 2006). Among the SCFFA, caprylic acid $\left(\mathrm{C}_{8}\right)$ is found to be significantly lower concentrations $(9.05,8.87 \mathrm{ppm})$ than other SCFFA in both cheeses with increasing storage period of $4 \mathrm{wk}$ $(p<0.05)$. The other SCFFA concentrations increase at higher level and follow the same trend with increasing storage period of $4 \mathrm{wk}$. In overall, SCFFA in CCWMP were found to be little higher than CRCCWMP from 0 to $4 \mathrm{wk}$ and confirmed that cholesterol removal caused some loss in the short-chain fatty acids in CCWMP.

In conclusion, qualitative and quantitative analyses of volatile compounds in whole milk powdered cream cheese confirmed that flavor compounds not effected during storage and showed similar volatile profiles to the whole milk-made cream cheese. Further cholesterol removal didn't cause much effect in volatile profiles of both cheeses. It also proved that fatty acids are the principal volatiles in both cream cheeses. Thus, this study confirmed that whole milk powder blended with cream is very effective in the making of cream cheese without affecting their volatile profiles.

\section{Acknowledgement}

This research was supported by the Brain Korea 21 Project in Seoul, Republic of Korea.

\section{References}

1. Adda, J. (1986) Flavor of dairy products. In: Developments in food flavors. Birch, G. G. and Lindley, M. G. (eds) Elsevier Applied Science, London, pp. 151-172.

2. Alewijn, M., Sliwinski, E. L., and Wouters, J. T. M. (2003) A fast and simple method for quantitative determination of fatderived medium and low-volatile compounds in cheese. Int. Dairy J. 13, 733-741.

3. AOAC (1984) Official methods of analysis. 10th ed, Association of Official Analytical Chemists, Washington, DC.

4. Attaie, R. (2009) Quantification of volatile compounds in goat milk Jack cheese using static headspace gas chromatography. J. Dairy Sci. 92, 2435-2443.

5. Carbonell, M., Nunez, M., and Fernandez-Garcia, E. (2002) Seasonal variation of volatile compounds in ewe raw milk La Serena cheese. Lait 82, 699-711.

6. Carunchia Whetstine, M. E., Drake, M. A., Nelson, B. K., and Barbano, D. (2006) Flavor profiles of full fat, reduced fat and cheese fat made from aged Cheddar with the fat removed using a novel process. J. Dairy Sci. 89, 505-517.

7. Chin, H. W., Bernhard, R. A., and Rosenberg, M. (1996) Solid phase microextraction for cheese volatile compound analysis. J. Food Sci. 61, 1118-1122.

8. Delgado, F. J., Gonzalez-Crespo, J., Cava, R., Garcia-Parra, J., and Ramirez, R. (2010) Characterization of the volatile profile of a Spanish ewe raw milk soft cheese P.D.O. Torta del Casar during ripening by SPME-GC-MS. Food Chem. 118, 182-189.

9. Han, E. M., Kim, S. H., Ahn, J., and Kwak, H. S. (2005) Cholesterol removal from homogenized milk with crosslinked $\beta$-cyclodextrin by adipic acid. Asian-Aust. J. Anim. Sci. 18, 1794-1799.

10. Jung, T. H., Ha, H. J., Ahn, J., and Kwak, H. S. (2008) Development of cholesterol-reduced mayonnaise with crosslinked $\beta$-cyclodextrin and added phytosterol. Korean J. Food Sci. Ani. Resour. 28, 211-217.

11. Kim, H. Y., Bae, H. Y., and Kwak, H. S. (2008) Development of cholesterol-reduced blue cheese made by crosslinked $\beta$ cyclodextrin. Milchwissenschaft 63, 53-56.

12. Kondyli, E., Katsiari, M., Masouras, T., and Voutsinas, L. (2002) Free fatty acids and volatile compounds of low-fat Feta-type cheese made with a commercial adjunct culture. Food Chem. 79, 199-205.

13. Kosikowski, F. V. and Mistry, V. V. (1997) Procedures and analyses. In: Cheese and fermented milk foods. Kosikowski, F. V. (ed) LLC, Westport, CT, pp. 212-214.

14. Kwak, H. S., Jeon, I. J., and Park, J. (1990) Effects of food grade porcine pancreatic lipase on the production of shortchain fatty acids and its contribution. Korean J. Food Sci. Technol. 22, 248-254.

15. Lee, J. H., Diono, R., Kim, G. Y., and Min, D. (2003) Optimization of solid phase microextraction analysis for the headspace volatile compounds of Parmesan cheese. J. Agric. Food Chem. 51, 1136-1140.

16. Molimard, P. and Spinnler, H. E. (1996) Review: Compounds involved in the flavor of surface mold-ripened cheeses: Origins and properties. J. Dairy Sci. 79, 169-184.

17. Patton, S. (1963) Volatile acids and the aroma of cheddar cheese. J. Dairy Sci. 46, 856.

18. Rychlik, M. and Bosset, J. O. (2001) Flavor and off-flavor compounds of Swiss Gruyère cheese. Identification of key odorants by quantitative instrumental and sensory studies. Int. Dairy J. 11, 903-910.

19. SAS (2002) SAS/STAT Software for Windows. Release 9.0, SAS Institute Inc., Cary, NC, USA.

20. Urbach, G. (1997) The avour of milk and dairy products. II. Cheese: contribution of volatile compounds. Int. J. Dairy Technol. 50, 79-89.

21. Van Leuven, I., Van Caelenberg, T., and Dirinck, P. (2008) Aroma characterisation of Gouda-type cheeses. Int. Dairy J. 18, 790-800.

(Received 2011.12.1/Accepted 2011.12.7) 